\title{
Exploring Student Success in a Doctoral Program: The Power of Mentorship and Research Engagement
}

\author{
Joshua Gisemba Bagaka's, Natale Badillo, Irina Bransteter \\ Cleveland State University, Cleveland, Ohio, USA \\ j.bagakas@csuohio.edu; nbadillo0219@gmail.com; \\ bransteter@aol.com \\ Sarah Rispinto \\ Cleveland Clinic Foundation, Cleveland, Ohio, USA \\ rispins@ccf.org
}

\begin{abstract}
The study explored features of an educational doctoral program that enhances doctoral student success. Doctoral student success is defined broadly to include not only completion and retention rates, but also the ability of the program to produce effective scholars in the field. The study utilized a mixed-method approach, incorporating quantitative and qualitative data from both alumni and current doctoral students. A total of 113 students participated in the survey and another 20 students participated in two parallel focus group discussions. A factor analysis of the 31-itemsurvey identified six dimensions representing different aspects of the doctoral program with an internal consistency measure of reliability ranging from 0.76 to 0.97 . Quantitative and qualitative findings converged in highlighting the importance of Program Support/Program Structure, Advisor Support/Faculty Mentorship, and Research Engagement/Formation of Scholars on doctoral students' success. These features incorporate effective socialization activities within the program. The study recommends that doctoral programs incorporate research engagement and effective mentorship activities into the program's structure for sustainable scholarship.
\end{abstract}

Keywords: mentorship, doctoral programs, research engagement, doctoral student success, formation of scholars, retention rates

\section{Introduction}

Material published as part of this publication, either on-line or in print, is copyrighted by the Informing Science Institute. Permission to make digital or paper copy of part or all of these works for personal or classroom use is granted without fee provided that the copies are not made or distributed for profit or commercial advantage AND that copies 1) bear this notice in full and 2) give the full citation on the first page. It is permissible to abstract these works so long as credit is given. To copy in all other cases or to republish or to post on a server or to redistribute to lists requires specific permission and payment of a fee. Contact Publisher@InformingScience.org to request redistribution permission.
Debate on student success has primarily focused on undergraduate students and programs; in this case, student success is measured in terms of dropout and graduation rates, and the length of time to degree completion. However, there is little research on graduate student success, particularly in doctoral programs, where there is anecdotal evidence that a large number of students who begin doctoral programs end up only as "All 
But Dissertation" (ABD). For instance, The Chronicle of Higher Education indicated there is a need for push for ABD's to 'cross the finish line' (Leatherman, 2000). Studies on student success in doctoral programs will need to begin by defining success in the context of doctoral programs. For example, Walker, Golde, Jones, Conklin Bueschel, and Hutchings (2008) discussed the issue of the formation of scholars as a measure of program effectiveness.

Doctoral students' success may then be seen in two ways. First is the quantitative one that ensures that students do not remain as ABD. When a large proportion of doctoral students end up as $\mathrm{ABD}$, it denies academic fields sufficient scholars with terminal degrees. Second is the qualitative one that emphasizes the formation of scholars. Pushing the ABD doctoral students to cross the finish line is necessary but not sufficient without producing scholars who are sufficiently grounded in the content and research in the field. Successful doctoral programs may then be defined as those that will produce effective scholars in the field as well as providing mechanisms and resources that will reduce attrition rates. The question, then, pertains to the identification of program features, as well as program practices, that promote the formation of scholars which increases the chances of students' completion rates. It is important to identify programs that incorporate aspects such as successful program mentorships and doctoral student engagement in research as part of their program activities.

It is estimated that approximately $50 \%$ of entering doctoral students fail to obtain their degree (D'Andrea, 2002; Johnson, Green, \& Kluever, 2000). These numbers are closely related to undergraduate students' completion rates (Berkner, He, \& Cataldi, 2002). The Chronicle's online academic discussion forum held on January 15, 2004 ("Why Do Graduate Students Drop Out?" 2004) addressed the question of why doctoral students drop out of the program. Though the forum generally acknowledged the lack of data on the subject, views of participants varied widely. One point of convergence among discussants was the fact that doctoral students, unlike during their prior years of schooling, work in an environment that is unstructured, requiring a great deal of independence. Without proper guidance and mentoring, such an environment can be disorienting for some students. Contact and interaction between students with peers and faculty members have been shown to be a factor in doctoral student completion rates (Pascarella \& Terenzini, 1977; Terenzini \& Pascarella, 1977). However, this contact need not just be with classroom or advising activities, but ought to go beyond that (Nagda, Gregerman, Jonides, von Hippel, \& Lerner, 1998; Pascarella \& Terenzini, 1977). For instance, Cockrell and Shelley (2011) revealed a positive relationship between doctoral students' satisfaction and the relationship with their advisor. Mason (2012) seemed to validate these findings but, in addition, found a positive relationship between students' feelings of autonomy over their research and their motivation to continue graduate school, highlighting the importance of mentorship while providing mentees academic space to form their own research identity.

Gardner (2008) argued that a "lack of socialization" in doctoral programs increases the risk for doctoral student attrition. The less a student fits the "expected" socialization pattern, the more likely a student is at risk of not finishing the doctoral program; this is especially true for students from underrepresented populations (women and students of color). Gildersleeve, Croom, and Vasquez (2011) stated that it is not uncommon for underrepresented students to experience "racialized aggressions" (p. 110), which may heavily impact students' emotional states. Ali and Kohun (2006) discussed students' feelings of isolation at four program stages of the Ph.D. study process including the following: a) preadmission to enrollment, b) the first program year, c) the second year until candidacy, and d) the dissertation stage. According to the authors, each program stage has its own unique stressors that can contribute to isolation. They stated, "confusion about program requirements can quickly turn into feelings of [being] overwhelm[ed] and being 'left behind"” (Ali \& Kohun, 2006, p. 24). 
Gardner (2008) concluded that not only did historically underrepresented students have difficulty with the socialization pattern, but so did nontraditional students (older students and/or students with children). Academic discipline and the educational environment of the academic institution ("institutional context") seem to also determine the impact of socialization (the problems of one school or department may not be the problems of another). Gardner suggested that institutions ought to offer more support, and that students should seek to become more involved (through student organizations and departmental committees), which would in turn help students find their place in the socialization "mold" of doctoral study programs.

According to Gildersleeve et al. (2011), faculty guidance is experienced through "socialization", which is defined as "...the process by which doctoral students learn the customs, traditions, and values of any given discipline or field through mentoring and advising relationships as well as by engaging in research, service, and teaching" (p. 94). How this process is put into place-and the aspects of its focus - varies within programs and institutions. The literature has discussed the presence of faculty-student mentorship, research engagement, and peer mentorship activities as examples of program features that can be effective in the formation of scholars as well as in enhancing doctoral students' completion rates.

\section{Mentorship}

A method of socialization utilized within graduate study programs is mentorship. In general, mentoring relationships can be either formal (as assigned by the program) or informal (naturally developing between the mentor and mentee). In doctoral programs however, most academic advisors evolve into the dual role of advisor and mentor, with a majority of them providing a wide range of support, including psychosocial and career mentorship. Mentorship activities are often shaped by the outcome needs of the program and the training needs of the students (Ali \& Kohun, 2006; Harty, Kormanyos, \& Enochs, 1983; Ward, Johnson, \& Campbell, 2004). Mentorship involves teaching, coaching, and giving personal and professional guidance (Dobie, Smith, \& Robins, 2010) usually for a fixed period of time (Hayes, 2005); for example, during the time that the student is working through the requirements of the graduate program (Dobie et al., 2010) or during a specific phase of the student's training (Hayes, 2005). University programs often have a heavier reliance on research-based mentorship activities (Ward et al., 2004).

$\mathrm{Hu}$, Thomas, and Lance (2008) also looked at the factors that appeared to promote the formation of mentoring relationships. They hypothesized that there were three factors that were most influential in the initiation of the mentoring relationship: similarity in race, sex, or age between the mentor and mentee; how the mentee views membership in his/her social group (defined by race, sex, or age), in terms of how their group has generally been treated by society; and how proactive the person appears to be with accomplishing tasks and goals in the eyes of others (the appearance of power, in the case of the mentor, or potential for success, in the case of the mentee).

Mentoring relationships can offer benefits for both the mentor and the mentee. For the mentee, the mentor can help increase the student's self-confidence and self-efficacy; give the student increased protection, support, and guidance during the socialization process; increase the level of the student's academic and professional progress; and provide unique opportunities for professional and personal growth in the culture of the organization (Hayes, 2005; Warren, 2005; White, 2007), as well as in the profession of choice (Cho, Ramanan \& Feldman, 2011). For the mentor, the relationship can help with "validating the mentor's efforts and status" (Hayes, 2005, p. 442) as the mentor observes the mentee's growth and encourages self-efficacy in the mentee (Hayes, 2005). The mentor also gains a future colleague and ally in the organization (White, 2007), as well as assistance with his or her work and greater exposure within the organization (Warren, 2005). The mentor, mentee, and organization all benefit from the student's socialization and guidance with the workings of the specific organization or institution (Hayes, 2005). The mentor 
is also a professional role model for the student in terms of professional involvement and behavior (White, 2007).

\section{Research Engagement}

Another important feature of doctoral student success, though seldom mentioned in the literature, is the level of engagement in academic research (Nagda et al., 1998). Although studies that have explored this issue of student engagement primarily utilized undergraduate students, results convey compelling evidence that student engagement in academic and educational activities should be considered when discussing doctoral students' success. For example, Hughes and Pace (2003) conducted a study with college students, concluding that students who are less engaged in such activities leave college earlier or without completion. Similarly, a more recent study with college students showed that student engagement had a significant impact on students' persistence and grades (Kuh, Cruce, Shoup, Kinzie, \& Gonyea, 2008). More recently, Lambie, Hayes, Griffith, Limberg, and Mullen (2014) showed that doctoral students' levels of engagement in research activities, including publishing manuscripts, have significantly higher levels of research selfefficacy, which is also related to research knowledge and productivity. Given that preparing scholars in the field is the primary goal of Ph.D. programs, it makes doctoral students' engagement in research activities critical in the formation of scholars.

\section{Peer Mentorship}

Reflexive conversations among graduate students and, in particular, doctoral students have revealed the extreme challenges, barriers, and hurdles of doctoral education and the pursuit of a doctoral degree: the infamous three letters doctoral students so adamantly strive to achieve - the Ph.D. In the seminal work of The Formation of Scholars, Walker and colleagues (2011) revealed the importance of moving doctoral education into the future. The challenges to doctoral education include high attrition rates, lack of financial resources, mismatch between opportunities and experiences, difficulties establishing support in addition to domestic responsibilities especially for non-traditional students. Creating opportunities and an environment that promotes scholars who are able to be successful and productive participants in the greater academic and educational research community is a challenging task that requires unwavering dedication (Hadjioannou, Shelton, Fu, \& Dhanarattigannon, 2007).

A new perspective is required when approaching doctoral student challenges. A key component in doctoral student success is the socialization process (Gardner, 2007) among peers and the support they provide each other. In addition, as Gardner (2007) points out, the majority of the extant literature encompasses all graduate school socialization, rather than examining the socialization and peer support by degree level. The importance of researching and understanding peer support by degree level is illustrated by Conrad, Duren, and Haworth (1998) in their work examining the dramatic differences in the structure and culture between master's and doctoral level education. Weidman, Twale, and Stein (2001) described four developmental stages of socialization in doctoral education: anticipatory stage, formal stage, informal stage, and personal stage. Within each of these stages, doctoral students are navigating their social experiences to foster developmental growth as a scholar by gaining knowledge, skills, and values necessary for completing their degrees and advancing their careers in the field.

Support is a vital factor for doctoral student retention and graduation. Although support can be operationalized in various forms, support for the purpose of doctoral education socialization will be viewed as peer support. In a qualitative study where Gardner (2007) conducted semistructured interviews with 20 full-time (twelve female and eight male) chemistry and history doctoral students, ranging from first-year to sixth-year study in their respective programs, a substantial proportion of these students identified peer support as a factor that plays a role in retention 
and completion. Gardner revealed that students approached more advanced students and sought information about the program and previous educational experiences they may have encountered. In addition, they sought guidance and support when determining which research groups to join and which professors were approachable and/or most informative.

Formally, peer-mentoring programs match novice students with more advanced students in their doctoral program to provide academic support, emotional support, and guidance as they maneuver through their own personal experiences (Brown, Davis, \& McClendon, 1999; Gardner, 2008). In addition, a study conducted by Grant-Vallone and Eshner (2000), concluded that peermentoring provided additional support for students. The additional support provided by students may be a necessary socializing support system set in place for overworked and overbooked faculty members, dissatisfaction with the quantity and quality of supervision or guidance received, and feelings of isolation or frustration that will surely ensue during doctoral education and training (Hadjioannou et al., 2007).

Peer mentoring may also be established informally, as students socialize more frequently and begin to relate their frustrations, anxiety, and fears to one another on a level that family members, partners, or friends may not understand. Hadjioannou et al. (2007) created "co-travelers" who provided support and encouragement as they navigated the doctoral student process. This coexperience provided an avenue for students to share their worries without the fear of being evaluated by their program.

Peer-mentoring encourages cohesiveness, inclusion, and support while refuting feelings of isolation that lead to failing to complete doctoral training. To examine the importance of cohort models, the University of California conducted a case study researching peer mentoring among students and faculty interactions (Dorn \& Papalewis, 1997). Students were assigned an individual peer mentor from an existing cohort and were advised to form a supportive, working relationship. This form of peer mentoring relationships is considered to be a cornerstone for the preparation and formation of scholars.

Regardless of the delivery model (cohort versus non-cohort, full versus part-time, residential versus commuter, etc.), the literature identifies several features that can be effective in doctoral students' success (program completion and formation of scholar with research skills). These features include but are not limited to faculty mentorship arrangements, research engagement, and peer mentorship activities. Programs often incorporate these features into their program through a variety of ways, including providing opportunities for teaching and research assistantships, linking students with faculty mentors, and promoting research partnerships between and among faculty and students. Effectively incorporating these features and practices into specific doctoral programs can be an important predictor of doctoral students' success.

\section{Purpose of the Study}

The purpose of the study is to explore doctoral program practices and features that enhance doctoral students' success, thus lending more information on how to make doctoral programs more effective. In the context of the study, program features include but are not limited to specific program requirements, organization, and human and physical resources provided to students. Specifically, the following research questions are addressed:

1. To what extent does the quality of faculty-student mentorship predict the success of doctoral students?

2. To what extent does student engagement in academic research predict doctoral students' satisfaction with the program?

3. Does peer mentorship have any influence on student success? 
4. What are some of the important features (requirements and resource provisions) of the doctoral program that enhance doctoral students' success?

\section{Significance of the Study}

Butz, Bloom, Gross, Kelly, Kofner, and Rippen (2003) analyzed the award of doctoral degrees in six broad fields between 1975 and 1999 and found Ph.D degree awards generally increased for 15 years and then leveled off and started to fall in 1998. Though studies to analyze recent trends beyond 2000 are scarce, Butz et al. (2003) noted that the awards of Ph.D to non-citizens in America in science, engineering, and health doctoral degrees has been increasing and may therefore account for a substantial proportion of overall degrees awarded. The number of doctoral degrees awarded to American citizens in these disciplines may be dropping.

An important benefit of increasing the quantity and quality of doctoral degrees completed is the link between research production and innovation in a society. Any nation will argue for increasing number of researchers in order to increase research output in various fields, in order to enhance development, innovation, and effective delivery of goods and services. Increasing doctoral students' completion rates as well as employing program features and activities that produce effective scholars should therefore be a desirable objective of doctoral programs.

\section{Research Methodology}

\section{Introduction}

The study utilized a mixed-method approach, incorporating quantitative and qualitative data from both alumni and current doctoral students. A survey was used to collect primarily quantitative data from alumni and current students. This method was considered effective in collecting data from participants (program alumni and current students) some of whom were geographically widely dispersed. In order to collect more detailed data from both current and graduate students, a qualitative methodology was also considered effective in examining the unique experiences of these participants while in the program. The use of qualitative data was beneficial in further understanding and validation of the quantitative findings as well as examining the role of nonquantifiable features of doctoral programs.

\section{Participants}

Participants for this study included current students enrolled in a traditional educational doctoral program at an urban university in the Midwest. In addition, alumni students who had graduated from the program over a fifteen-year period were also included in this study. Students in the specializations of Leadership and Lifelong Learning, Learning and Development, Policy Studies, Counseling Psychology, and School Administration were represented in the study. Table 1 presents the number and percentage of participants by various demographic characteristics. A total of 115 participated in the survey, of whom 80 (or 69.6\%) were current students and 33 (or 30.4\%) alumni. Seventy-three percent of the survey participants were female. Breakdown by employment and student status shows that 81 (or 70.4\%) were employed full-time and 51 (or $44.3 \%$ ) were full-time students, indicating that a substantial proportion of these doctoral students were full-time in both employment and doctoral studies while pursuing their doctoral studies. Twentyseven (or 23.5\%) of the participants were on graduate assistantship while pursuing their studies. In addition to the 115 survey participants and addition 20 students participated in two parallel focus group discussions. 
Table 1: Number and percentage of survey participants by various demographic characteristics

\begin{tabular}{llcc}
\hline \multicolumn{1}{c}{ Characteristic } & \multicolumn{1}{c}{ Levels } & Number & Percentage \\
\hline Participant Status & Current Student & 80 & 69.6 \\
& Alumni & 35 & 30.4 \\
\hline Gender & Male & 30 & 26.1 \\
& Female & 83 & 72.2 \\
& No answer & 2 & 1.7 \\
\hline Race & White & 81 & 70.4 \\
& Black & 23 & 20.0 \\
& Other & 11 & 9.6 \\
\hline Student Status & Full-time & 51 & 44.3 \\
& Part-time & 64 & 55.7 \\
\hline Employment Status & Full-time & 82 & 71.3 \\
& Part-time & 19 & 16.5 \\
& Not employed & 14 & 12.2 \\
\hline Graduate Assistantship & Yes & 34 & 29.6 \\
& No & 81 & 70.4 \\
\hline
\end{tabular}

\section{Instrumentation}

The survey monkey instrument used in the study had five sections in addition to one section of demographic characteristics and another on graduate assistantship experience. The five sections with a combined 41 items covered students' perceived involvement and experience in groups interactions (faculty and/or other students), doctoral program support, level of research engagement, and overall satisfaction with the program experience and were rated on a four-point Likerttype scale: (1) Strongly Disagree (2) Disagree (3) Agree (4) Strongly Agree.

\section{Data Collection Procedure}

Once necessary permissions and IRB approval was granted, a survey was distributed to all alumni and current students of the program. In order to triangulate the data in the study, two focus groups were held: one for alumni and one for current students. A series of questions were provided in each focus group to prompt an open discussion regarding their personal experiences regarding research engagement, faculty mentoring, group and peer interaction, and perceived levels of support. Each of the focus group discussions were administered by individuals outside the research team. Notes were taken and concurrently digitally recorded for validation purpose in transcription of the data.

\section{Data Analysis}

The principle component factor analysis was used to identify dimensions of student experience in the program, including research engagement, faculty mentoring, peer mentoring/interaction, program support, and the overall perception of student success. In this case, dimensions are defined as constructs that capture aspects of the program that were used as predictors of student success. These dimensions are treated as primary predictor variables of the study. Consequently, a multiple linear regression model was used to determine the extent to which these dimensions (constructs) of the program predict doctoral student success and satisfaction in the program. 
The approach to the qualitative data used the Consensual Qualitative Research model (Hill, Knox, Thompson, Nutt Williams, and Hess, 2005). This approach was employed to explore the qualitative data analysis for several reasons. The semi-structured focus groups were open-ended allowing for a more in-depth examination of individual and group experiences. The data collected was analyzed by three separate researchers that allowed for multiple perspectives on the overarching domains and codes embedded in each student experience. Once a consensus was reached regarding the domains and codes, an outside, fourth researcher audited the transcripts to ensure the quality of work (Hill et al., 2005).

The mixed method approach provided researchers with a better understanding of the extent to which variables play a role in student success, as well as, how their unique experiences impacted the way they interacted with peers, faculty, and their overall doctoral studies environment.

\section{Findings}

\section{Quantitative Findings}

A factor analysis of the 31 items from five sections of the survey identified six dimensions representing different aspects of the doctoral program. Based on the items that loaded into each of these factors, the following dimension were identified:

1. General Quality and Structure of the Program: This dimension captured the general structure and organization of the program, including effective communication with program leadership. The item on the availability of courses when needed also loaded into this dimension.

2. Group Interaction: Items that represented intra- and inter-specialization interaction with colleagues within the program, as well as collaboration with other graduate students across the university, capture the main features of this dimension. Items in this factor also included those that linked these interactions with persistence in the program and fostering positive relationships with other graduate students.

3. Quality of Program Support: The six items that loaded into this factor captured the quality of support students received from program staff and interactions with faculty who taught doctoral courses. Some items in this factor showed the value of prompt feedback from faculty.

4. Quality of Advisor Support: The two items that defined this dimension focused on the quality of advisor support and availability. Accessibility of the faculty advisor and willingness to spend time with the student are important aspects of this dimension.

5. Research Engagement: The items that captured this dimension were related to aspects that encouraged and provided support to engage in research activities. Items that captured the extent to which students are provided with opportunities to collaborate with faculty and other students in doing research loaded into this factor. Some items in this factor assessed the value of opportunities the present at research conferences and publishing in refereed journals.

6. General Satisfaction: The items that captured students' level of satisfaction with the overall doctoral experience, skills so far acquired, as well as quality on mentorship received were represented in this dimension.

Each of these six dimensions was internally consistent with the Cronbach's Alpha reliability ranging from 0.76 to 0.97 (see Table 2). Items that loaded into each of these factors were used to create composite variables representing the six dimension of the doctoral program. These dimen- 
sions represented important variables of the study along with certain participants' demographic characteristics.

Table 2: Cronbach's Alpha reliability coefficients for the six dimensions of the doctoral program

\begin{tabular}{lcc}
\hline \multicolumn{1}{c}{ Dimension } & \# of items & Alpha \\
\hline General Quality of the Program & 6 & 0.875 \\
Group Interaction & 8 & 0.812 \\
Quality of Program Support & 6 & 0.934 \\
Quality of Advisor Support & 2 & 0.968 \\
Research Engagement & 5 & 0.770 \\
General program Satisfaction & 4 & 0.762 \\
\hline
\end{tabular}

The multiple linear regression model was used to determine the extent to which various aspects of the doctoral program (Dimensions 1-5) can predict students' satisfaction with the overall doctoral program (Dimension 6). The findings presented in Table 3 show that the general quality of the academic program $(\beta=0.37, p<0.01)$, quality of program support $(\beta=0.28, p<0.01)$, advisor support $(\beta=0.18, \mathrm{p}<0.01)$, research engagement $(\beta=0.13, p=0.026)$, and gender $(\beta=0.13, p=$ $0.030)$ were significant predictors of the overall satisfaction with the doctoral program. However, group interaction $(\beta=0.07, p=0.293$ ) was a positive though not a statistically significant predictor of the overall satisfaction with the doctoral program. All the significant predictors were positively related to the overall satisfaction with the doctoral program. In addition, the data shows that female doctoral students had a significantly higher level of satisfaction with the program than their male counterparts. The model accounted for approximately $67 \%$ of the variance in doctoral students' overall satisfaction with the program.

Table 3: Multiple Regression results for the prediction of overall satisfaction with the doctoral program by five aspects of the program

\section{Regression Coefficients}

\begin{tabular}{lccc}
\hline Predictor & $B$ & Beta & $p$-value \\
Gender (0 = male, 1 = female) & 0.14 & 0.13 & 0.030 \\
General Quality of the Program & 0.36 & 0.37 & 0.000 \\
Group Interaction & 0.07 & 0.07 & 0.293 \\
Quality of Program Support & 0.25 & 0.28 & 0.002 \\
Quality of Advisor Support & 0.18 & 0.25 & 0.000 \\
Research Engagement & 0.13 & 0.14 & 0.026 \\
\hline
\end{tabular}




\section{Qualitative Findings}

A consensual qualitative analysis of the focus group data identified seven domains that represent important features of the doctoral program. Domains are part of qualitative research lingo and are comparable to dimensions or constructs identified in the quantitative portion of analysis. Domains are defined as key topics or themes extracted from the qualitative data collected. In this study domains that emerged were 1) cohort model, 2) program structure, 3) formation of scholars, 4) faculty mentorship, 5) dissertation process, 6) program funding, and 7) traditional versus nontraditional students.

\section{Cohort model}

The cohort model was developed as a response to a decline in student retention and graduation rates in United States and United Kingdom, as well as to increase general success of higher education students (Lei, Gorelick, Short, Smallwood, \& Wright-Porter, 2011). Basically, a cohort is a group of students, ranging anywhere from 10 to 25 , that start a given doctoral program at the same time and experience the educational process together, finishing roughly around the same time (Barnett, Basom, Yerkes, \& Norris, 2000; Maher, 2005; Nimer, 2009). In addition, cohort model programs offer planned courses (which could potentially ease students' anxiety and save time), professional development opportunities, faculty mentoring, group collaboration, social and emotional support, as well as guided dissertation process support (Nimer, 2009).

In addition to the above-mentioned benefits of the cohort model, the cohort model domain in this study provided doctoral students with an opportunity for peer mentorship, which gave them an additional support system. In general, a cohort system provides a learning space where doctoral students can present their personal work, as well as review and critique their peers' work (De Lange, Pillay, \& Chikoko, 2011). In this study, the cohort model domain consisted of two distinct levels of peer mentoring, namely, intra and inter cohort peer mentoring. An extension of peer mentorship referred to as "peer couples," emerged as an added advantage of the cohort model, which will be further explored in future research projects. Below is an example of an intra and inter cohort subcategory statement, as provided by a student who graduated from the program:

Well, I thought it was a good experience. Particularly liked the cohort system [and] work with colleagues to get me through rough spots in [statistics] from time to time. Plus it seems at least [that for] much of the course work the professors were in tune to what was good instructional process and techniques, which allowed for a lot of collaborative learning and [professors] knew that worked well to motivate the students.

The "cohort" domain and "peer mentorship" sub-domain, as is contained in the qualitative descriptions given by participants in this study, highlight the importance of the intra- and intercohort interactive feature inherent in cohort models.

\section{Program structure}

The "program structure" domain consisted of the following subcategories: scheduling issues, multidisciplinary learning experience, and organization and accessibility of the program. An example of the scheduling issues domain would be:

At times frustrating when needed classes aren't offered, but required, but not available. Attempting to schedule your life around a program that said it's going to be available for evening doctoral students.

Multidimensional learning concerns itself with different fields of study being united through this specific program. All of the before mentioned tracks of study would be united through common 
class work required of all the attending students, regardless of the track of study. Some examples embodying this subcategory would be:

I'm interested [in] nursing. For the psych[ology] people, they didn't feel "drawn in" by the non-psych[ology] faculty. There are so many factors.

Frustration. Wondering why we're taking specific courses. ... The connection between the courses and our specialization.

Professors need to address the syllabus of the class to meet the needs (specialization) of the cohort.

The "organization and accessibility of the program" subcategory reflects the general organization of the program, as well as accessibility of resources. A current student stated the following about organization and accessibility:

We know of people who have left. Lot of frustrations about classes. You can't meet with your advisor in the evening because the advisor can't work in the evening.

\section{Formation of scholars}

The "formation of scholars" domain included research skill building, networking, publishing, practice in the field, and degree of fit for graduate assistant/teaching assistant (GA/TA) and students' interests categories. Such scholarly involvements, especially research engagement, have been identified as fundamental factors in doctoral student success (Gardner, 2007; Pyhältö, Vekkaila, \& Keskinen, 2012). In addition, the perceived fit between students and their working environment (whether GA/TA position or voluntary research position) tends to govern their general educational engagement (Leech, 2012). This domain is mainly concerned with the creation of scholars and future professionals. Examples embodying this domain and its subcategories are as follows:

I think at the dissertation stage, when I was doing qualitative [research], it required a lot. The time and effort it involved in trying to finish it up and work so there were times when I said 'eh' you know, but for me it was closure. I never start something I can't close out. I am going to see this through. So I worked through [the statistics]. I stuck it out.

I presented with different professors at conferences. We have a paper we're tweaking for publication.

I've been able to use the strategies learned in class in my profession, especially stats. I was able to practice and make it relevant in my field instead of in a hypothetical situation.

\section{Faculty mentorship}

The "faculty mentorship" domain included faculty encouragement of participation with scholarly endeavors, as well as the provision of emotional support through academic and non-academic challenges. These factors have been deemed as important throughout the literature, underscoring the importance of faculty involvement (Brailsford, 2010; Sambrook, Stewart, \& Roberts, 2008). Examples of statements related to the "faculty mentorship" domain in this study were as follows:

I thought the push to present your work is beneficial...for your resume.

I've had a lot of trouble with people on my dissertation committee. I was not notified that one of my committee members no longer works here. Another person got a Fulbrightthey wanted me to wait to defend for a year. I said no. I don't know if there's a policy 
when someone leaves [the University]. It's extremely frustrating at the end. I have to change advisors now. No one has ever told me.

I think that is a part of the faculty teaching. One past faculty member didn't like psych[ology] students. Depending on the luck of the draw, they are going to be less amenable to psych students.

\section{Dissertation process}

The "dissertation process" domain concerned itself with the entire dissertation process. It included the categories of peer and faculty support during dissertation work, and the dissertation initiation process. Statements embodying the dissertation process were as follows:

People who are GA's, it's easy to put their dissertation committee together. Putting together the committee was difficult for me. If you have the right advisor that's helpful. And the cohort is helpful.

When we get to the prospectus and dissertation, can we have a time limit that the professors look at?

I think that the progression of classes is good. I think some professors have structured their classes toward comp[rehensive exams]. That is beneficial. Some professors have really emphasized from the start of the program to do the work you're going to [do] your dissertation on.

\section{Program funding}

The domain of "program funding" included financial concerns that accompany the process of doctoral program study. In one mixed-method study, doctoral program faculty (doctoral student supervisors) had identified financial issues as the key resources and /or challenges in the doctoral program process (Pyhältö et al., 2012). Another qualitative study exploring school and work balance in doctoral students found that students perceived financial support as one of the key elements in managing different roles and achieving balance (Martinez, Ordu, Della Sala \& McFarlane, 2013). Examples of opinions given by current and alumni students follow:

No benefits, no unemployment, [they] don't last the duration of the program. You can't live off of $\$ 800.00$ a month - that's below the poverty level. It's difficult!

I think back now, the paper for the questionnaires (and I color coded), postage alone, self-addressed envelopes, and some of the committee members encouraged me to include a pen so that they had no excuse to not fill it out. One participant's pen was damaged and he left me a note so I sent him another pen. But you are right that [there are] expenses at the end. If you are not working that can certainly be a challenge to overcome because you are planning to finish but data collection is on hold because of no funding.

\section{Traditional versus nontraditional students}

This domain focused on the similarities and differences of traditional (full-time day students) and nontraditional (part-time, evening, and mostly off campus students). Part-time doctoral program attendance has been somewhat discouraged (Gardner \& Gopaul, 2012); however, for some, this is the only option as they struggle to balance school, work, and personal life (Martinez et al., 2013). Subcategories for this domain were personal stressors, academic stressors, and balancing roles as categories within this domain. Examples illustrating this domain and its subcategories were as follows: 
I can only take one class at a time. I live so far away I can only get in contact with professors by e-mail or phone.

The representatives were always full-time people at [the University]. How are they representing me, a commuting student? Maybe there needs to be a "commuter representative".

There are commuter students and people who work here at [the University] as a GA or an employee. They get to know professors in different areas.

We had one person leave our cohort because they got a job promotion. They felt they couldn't balance the two.

\section{Convergence of Quantitative and Qualitative Findings}

Although the quantitative and qualitative approaches offered different perspectives, the findings converged to a great extent. The quantitative approach identified the Quality of Program Support as a significant predictor of student success, as well as did the qualitative analysis. Both approaches identified support in the program, whether from the faculty or other students, to be an important determinant of student success. Another convergence occurred between the quantitative dimension of Quality of Advisor Support and the qualitative domain of Faculty Mentorship, as well as the quantitative dimension of Research Engagement and the qualitative domain of Formation of scholars. The later pair of factors is concerned with research engagement of students that include features such as, support for research, providing opportunities for conference presentations, and publishing.

\section{Summary}

Research on student success has primarily focused on undergraduate students. In that context, student success is viewed in terms of student retention and graduation rates, as well as time to completion. Research on graduate student success is rather challenging in multiple ways. First, there is the scarcity of research in this important area. Secondly, there seems to be a lack of a universal acceptable definition of graduate student success, particularly at the doctoral level. Retention, graduation rates, and time to completion do not accurately reflect a doctoral student's educational success. For instance, a doctoral student who may take longer to complete a program but ends up publishing multiple articles prior to completing his/her dissertation may be viewed as more successful than one who completes the program in the shortest time possible, but with little research or mentorship experience.

In this study, there are three important findings that converged, through examination of the quantitative and qualitative findings that highlight the most important features of doctoral students' perceived success. They include program support and structure, opportunities for research and research formation, support on faculty and student level, as well as the general structure and organization of the program.

\section{Program Support/Cohort Model}

The aspect of program support, highlighted in the quantitative findings, converged with the qualitative finding inherent in the cohort model domain.

2. Advisor Support/Faculty Mentorship

The aspect of advisor support, highlighted in the quantitative findings, converged with the qualitative findings of faculty mentorship.

3. Research Engagement/Formation of Scholars 
The aspect of research engagement, highlighted in the quantitative findings, converged with the qualitative findings of formation of scholars. These findings highlight the importance of the formation of scholars as a fundamental purpose of doctoral education.

As previously discussed, the quantitatively identified Quality of Program Support dimension is a significant predictor of student success, as well as is the qualitative domain of the Cohort Model. Both of the qualitative and quantitative student success predictors are defined by additional support, whether from the faculty and staff or other students. The second identified convergence of data occurred between the quantitative predictive factor of Quality of Advisor Support and qualitative predictor of Faculty Mentorship. Both significant factors are referring to faculty and advisor involvement and support throughout the program duration. The third convergence of data outcomes occurred with the quantitative dimension of Research Engagement and the qualitative domain of Formation of scholars. Both of these significant factors were concerned with research engagement of students, which, as previously stated, refer to such qualities as encouragement, support, opportunities for research, as well as necessary skills and confidence building. The fourth and last convergence between the qualitative and quantitative data was evident with the General Quality of the Program, which emerged from quantitative data, and the Program Structure from qualitative data, both concerning themselves with general structure and organization of the program, such as available courses and scheduling concerns and organization and accessibility of the program and program leadership. These factors are further linked to students' level of satisfaction with their doctoral programs and contribute to student persistence, retention, and successful program completion.

\section{Discussion}

The features we have identified that make doctoral programs more effective involve necessary socialization activities within the program (e.g., personal interaction, which may involve faculty and students attending conferences together, meeting in small groups to discuss research, and one-to one guidance with reviewing research skills and techniques required for presentation or publication). Hlebec, Kogovšek, and Ferligoj (2011) conducted a quantitative study that demonstrated social support, via the doctoral student's academically related network of colleagues and/or supervisors within the doctoral program, as the most statistically significant predictor of successful work completion.

The concept of socialization is here seen as an underlying theme in doctoral student success, whether with faculty or among student peers. Lei et al. (2011) discussed the concept of "social interdependence" (p. 498) and building a network, within the cohort structure, of community members providing continuous academic and emotional support for students to achieve learning goals in their programs of study more easily. These same views are highlighted in Gardner (2007). Maher, Falluca, and Mulhern Halasz (2013) also investigated the implementation of this concept through the process of doctoral writing groups. Writing group activities have been offered as an option for doctoral candidates within programs of study, as well as through face-toface resources outside of the program context (Leatherman, 2000; Offerman, 2011). There is also a great deal of verbal and nonverbal professional role modeling by faculty members that takes place during such interactions, which cannot be replaced by technology (Cockrell \& Shelley, 2010; Hlebec et al., 2011).

Previous studies have demonstrated the importance of socialization into the culture of the doctoral program (Gardner, 2007; Pyhältö et al., 2012). While difficulties with gaining face-to-face meeting time can also be a disadvantage in traditional programs - where a student and a faculty member may, for a period of time, have difficulty meeting due to scheduling conflicts and constraints - the aspect of increased isolation and separation from personalized academic guidance 
over an extended period may be detrimental to the program satisfaction factors defined by this study. There is also the disadvantage of diminished opportunity for immersion into the culture of the academic environment (Pascarella \& Terenzini, 1977; Terenzini \& Pascarella, 1977).

\section{The Non-Traditional Doctoral Student}

Offerman (2001) stated that structured development of cohort model doctoral programs is "designed to create a clear path to success" (p. 29), particularly for the non-traditional doctoral student. This brings the dilemma of the non-traditional student to the forefront of our discussion. The non-traditional student is often older, typically in the age range of 30 s to 40 s (Pearson, Evans, \& Macauley, 2004); within the past decade, the average age of the doctoral student was 33.3 years (Offerman, 2011). The non-traditional student often has limited time and access to offerings within the format of traditional doctoral programs, often due to occupational and/or family-based demands. Many have the responsibilities of professional occupations, partners, children, and/or aging parents in addition to academic study (Martinez et al., 2013; Offerman, 2011), which often leads to a preference for seeking a doctoral degree through part-time study. In order to create more accessible doctoral programs for this population, however, we may compromise the benefits of mentorship and faculty support that have become an integral part of traditional doctoral program structures, which leads to the non-traditional student meeting with advisors and/or mentors on a "part-time, intermittent basis" (Offerman, 2011, p.27) instead of full immersion into the world of academia - a standard expectation of traditionally-designed Ph.D. programs (Martinez et al., 2013; Offerman, 2011).

\section{Recommendations}

\section{Program Structure}

The development of flexible instructional opportunities (the combination of face-to-face and online instruction) needs to be continuously emphasized, so as to not lose sight of socialization aspects of the doctoral program. Interaction with peers (as, with our study example, inter- and intra-cohort experiences) and faculty mentorship opportunities (particularly co-publishing and copresentation opportunities) are valuable aspects to incorporate for doctoral student success, while directing attentiveness to aspects of program access and program accommodation aspects for nontraditional students. Non-traditional students may benefit most from the intra- and inter-cohort aspects of doctoral programs, due to the variations in student perspectives based on sociallyrelated aspects such as ethnicity, employment, and family experiences (Martinez et al., 2013; Pearson et al., 2004).

The cohort aspect, in our study, proved to be a related benefit to all students - traditional and nontraditional - to promote student success and program completion. The richness of multicultural instruction, defined by the varied experiences of faculty in research and practice perspectives, also provides a strong foundation for students to see examples of professional modeling from more diverse perspectives along the mentorship journey. In the features of the aspect of the program studied, the diversity of faculty mentors from various research and practice specializations adds to the richness of perspectives presented to students during their course of study. Students expressed possible benefits from multicultural and multidisciplinary experiences provided by faculty mentors within the context of a defined academic community, particularly when faculty members offered mentorship opportunities within a flexible framework that allows the student to balance academic, professional, and personal demands more easily (Leatherman, 2000; Martinez et al., 2013; Pappas \& Jerman, 2011; Pyhältö et al., 2012). 


\section{Emphasis on Formation of Scholars}

The emphasis on activities relating to the formation of scholars and research engagement (e.g., joint publications, joint presentations, mentoring (by peers and faculty), and introduction into the professional culture) contributes to what we refer to as "sustainable scholarship." For example, in the program studied, students who were mentored in their first year in their cohort often become mentors to the newer students that follow, creating a hierarchy of mentorship activity.

\section{Limitations of the Study}

This study was limited by the fact that the research was conducted on one doctoral program located at a medium-sized Midwestern university, which may limit generalizability to other university populations. Also, the doctoral program examined was one based on the experiences of students within the university's College of Education; therefore, the experiences of these students may not be aligned with other doctoral students in non-educationally based programs of study (e.g., scientifically-based programs of study such as neuroscience, biology, or chemistry). Since this study was conducted with alumni and current students of the program, one possible limitation is that the accuracy of information from the alumni depends on long-term memory of their experiences while in the program. However, there are fundamental similarities across doctoral programs regardless of discipline.

\section{Recommendations for Further Research}

One aspect in particular that emerged from the qualitative findings - discussion regarding the development of cohort member peer-to-peer support-will be examined in the context of what our research team has identified and named as "Ph.D. Couples." Interestingly enough, these peersupport relationships appeared both within the same cohort (intra-cohort) as well as across cohorts (inter-cohort), depending on the doctoral course of study and aligned goals of the students involved.

Based on the findings of this study, more studies involving a mixed-method research approach should be considered. While the statistical rigor of the findings allows for further exploration and investigation in the quantitative realm, qualitative investigation incorporated in this study provided the richness of response needed to emphasize important aspects that emerged from questions that were not specifically asked by the researchers. The focus group format especially provided the depth of detail related to significant aspects of student success that may not have otherwise been discovered. Although "group interaction" was not found to be significant in the quantitative realm, it was closely connected to a significant element of the qualitative findings that will likely emerge as a fundamental aspect of a future study. In the process of qualitative exploration in this study, the cohort model aspect of doctoral study was a significant contributor to the element of student success and program satisfaction. In future research, these aspects of the cohort modelintra-cohort, as well as inter-cohort activities - will be further explored. In the case of this study, both approaches were necessary and integral parts of exploring the research questions presented, and convergence of the quantitative and qualitative findings enhanced the research investigation.

\section{References}

Ali, A., \& Kohun, F. (2006). Dealing with isolation feelings in IS doctoral programs. International Journal of Doctoral Studies, 1, 21-33. Retrieved from http://www.ijds.org/Volume1/IJDSv1p021-033Ali13.pdf

Brailsford, I. (2010). Motives and aspirations for doctoral study: Career, personal, and inter-personal factors in the decision to embark on history PhD. International Journal of Doctoral Studies, 5, 15-27. Retrieved from http://ijds.org/Volume5/IJDSv5p015-027Brailsford283.pdf 
Berkner, L., He, S., \& Cataldi, E. F. (2002). Descriptive summary of 1995-96 beginning postsecondary students: Six years later (NCES 2003-151). Washington, DC: U.S. Department of Education, National Center for Education Statistics.

Barnett, B. G., Basom, M. R., Yerkes, D. M., \& Norris, C. J. (2000). Cohorts in educational leadership programs: Benefits, difficulties, and the potential for developing school leaders. Educational Administration Quarterly, 36(2), 255-282.

Brown, M. C., Davis, G. L., \& McClendon, S. A. (1999). Mentoring graduate students of color: Myths, models, and modes. Peabody Journal of Education, 74, 105-118.

Butz, W., Bloom, G., Gross, M., Kelly, K., Kofner, A., \& Rippen, H. (2003). Is there a shortage of scientist and engineers? RAND: Issue Paper, 1-9.

Cho, C. S., Ramanan, R. A., \& Feldman, M. D. (2011). Defining the ideal qualities of mentorship: A qualitative analysis of the characteristics of outstanding mentors. The American Journal of Medicine, 124(5), 453-458.

Cockrell, C., \& Shelley, K. (2010). The relationship between academic support systems and intended persistence in doctoral education. Journal of College Student Retention: Research, Theory, \& Practice, 12(4), 469-484.

Conrad, C. F., Duren, K. M., \& Haworth, J. G. (1998). Students' perspectives on their master's degree experiences: Disturbing the conventional wisdom. New Directions for Higher Education, 101, 65-76.

D'Andrea, L. M. (2002). Obstacles to completion of the doctoral degree in colleges of education: The professors' perspective. Educational Research Quarterly, 25(3), 42-58.

De Lange, N., Pillay, G., \& Chikoko, V. (2011). Doctoral learning: A case for a cohort model of supervision and support. South African Journal of Education, 31(1), 15-30.

Dobie, S., Smith, S., \& Robins, L. (2010). How assigned faculty mentors view their mentoring relationships: An interview study of mentors in medical education. Mentoring \& Tutoring: Partnerships in Learning, 18, 4.

Dorn, S. M., \& Papalewis, R. (1997). Improving doctoral student retention. Paper presented at the Annual Meeting of the American Educational Research Association (Chicago, IL, March 24-28).

Gardner, S. K. (2007). "I heard it through the grapevine": Doctoral student socialization in chemistry and history. Higher Education, 54, 723-740.

Gardner, S. K. (2008). Fitting the mold of graduate school: A qualitative study of socialization in doctoral education. Innovative Higher Education, 33(2), 125-138.

Gardner, S. K., \& Gopaul, B. (2012). The part-time doctoral student experience. International Journal of Doctoral Studies, 7, 63-78. Retrieved from http://ijds.org/Volume7/IJDSv7p063-078Gardner352.pdf

Gildersleeve, R. E., Croom, N. N., \& Vasquez, P. L. (2011). “Am I going crazy?!”: A critical race analysis of doctoral education. Equity \& Excellence in Education, 44(1), 93-114.

Grant-Vallone, E. J., \& Ensher, E. A. (2000). Effects of peer mentoring on types of mentoring support, program satisfaction and graduate student stress: A dyadic perspective. Journal of College Student Development, 41, 637-42.

Hadjioannou, X., Shelton, N. R., Fu, D., \& Dhanarattgannon, J. (2007). The road to a doctoral degree: Cotravelers through a perilous passage. College Student Journal, 41, 1.

Harty, H. H., Kormanyos, E. C., \& Enochs, L. G. (1983). Students' eye view of an external doctoral program's first-year summer residency training. Alternative Higher Education, 7(2), 80-90.

Hayes, E. F. (2005). Approaches to mentoring: How to mentor and be mentored. Journal of the American Academy of Nurse Practitioners, 17(11), 442-445.

Hill, C.E., Knox, S., Thompson, B.J., Nutt Williams, E., \& Hess, S.A. (2005). Consensual qualitative research: An update. Journal of Counseling Psychology, 52(2), 196-205. 
Hlebec, V., Kogovšek, T., \& Ferligoj, A. (2011). The influence of social support and personal networks on doctoral student performance. Advances in Methodology \& Statistics /Metodoloski Zvezki, 8(2), 157171 .

Hu, C., Thomas, K. M., \& Lance, C. E. (2008). Intentions to initiate mentoring relationships: Understanding the impact of race, proactivity, feelings of deprivation, and relationship roles. The Journal of Social Psychology, 148(6), 727-744.

Hughes, R., \& Pace, C. R. (2003). Using NSSE to study student retention and withdrawal. Assessment Update, 15(4), 1-2.

Johnson, E. M., Green, K. E., \& Kluever, R. C. (2000). Psychometric characteristics of the revised procrastination inventory. Research in Higher Education, 41(2), 269-279.

Kuh, G. D., Cruce, T. M., Shoup, R., Kinzie, J., \& Gonyea, R. M. (2008). Unmasking the effects of student engagement on first-year college grades and persistence. The Journal of Higher Education, 79(5), 540563.

Lambie, G. W., Hayes, B. G., Griffith, C., Limberg, D., \& Mullen, P. R. (2014). An exploratory investigation of the research self-efficacy, interest in research, and research knowledge of $\mathrm{Ph}$. $\mathrm{D}$. in education students. Innovative Higher Education, 39(2), 139-153.

Leatherman, C. (2000). A new push for ABDs to cross the finish line. The Chronicle of Higher Education, 46(29), A18-A20.

Leech, N. L. (2012). Educating knowledgeable and skilled researchers in doctoral programs in schools of education: A new model. International Journal of Doctoral Studies, 7, 19-37.

Lei, S., Gorelick, D., Short, K., Smallwood, L., \& Wright-Porter, K. (2011). Academic cohorts: Benefits and drawbacks of being a member of a community of learners. Education, 131(3), 497-504.

Maher, M. (2005). The evolving meaning and influence of cohort membership. Innovative Higher Education, 30(3), 195-211.

Maher, M., Fallucca, A., \& Mulhern Halasz, H. (2013). Write On! Through to the Ph.D.: Using writing groups to facilitate doctoral degree progress. Studies in Continuing Education, 35(2), 193-208.

Martinez, E., Ordu, C., Della Sala, M. R., \& McFarlane, A. (2013). Striving to obtain a school-work-life balance: The full-time doctoral student. International Journal of Doctoral Studies, 8, 39-59. Retrieved from http://ijds.org/Volume8/IJDSv8p039-059Martinez0375.pdf

Mason, M. M. (2012). Motivation, satisfaction, and innate psychological needs. International Journal of Doctoral Studies, 7, 259-277. Retrieved from http://ijds.org/Volume7/IJDSv7p259-277Mason0345.pdf

Nagda, B. A., Gregerman, S. R., Jonides, J., von Hippel, W., \& Lerner, J. S. (1998). Undergraduate student-faculty research partnerships affect student retention. The Review of Higher Education, 22(1), 5572.

Nimer, M. (2009). The doctoral cohort model: Increasing opportunities for success. College Student Journal, 43(4), 1373-1379.

Offerman, M. (2011). Profile of the nontraditional doctoral degree student. New Directions for Adult \& Continuing Education, 129, 21-30. doi:10.1002/ace.397

Pappas, J. P., \& Jerman, J. (2011). Editors' notes. New Directions for Adult \& Continuing Education, 129, 1-5. doi:10.1002/ace.395

Pascarella, E. T., \& Terenzini, P. T. (1977). Patterns of student-faculty informal interaction beyond the classroom and voluntary freshman attrition. Journal of Higher Education, 48(4), 540-552.

Pearson, M., Evans, T., \& Macauley, P. (2004). The working life of doctoral students: Challenges for research education and training. Studies in Continuing Education, 26(3), 347-353.

doi:10.1080/0158037042000265917 
Pyhältö, K., Vekkaila, J., \& Keskinen, J. (2012). Exploring the fit between doctoral students' and supervisors' perceptions of resources and challenges vis-à-vis the doctoral journey. International Journal of Doctoral Studies, 7, 395-414. Retrieved from http://ijds.org/Volume7/IJDSv7p395-414Pyhalto383.pdf

Sambrook, S., Stewart, J., \& Roberts, C. (2008). Doctoral supervision . . . a view from above, below, and the middle! Journal of Further and Higher Education, 32(1), 71-84.

Terenzini, P. T., \& Pascarella, E. T. (1977). Voluntary freshman attrition and patterns of social and academic integration in a university: A test of a conceptual model. Research in Higher Education, 6(1), 109-127.

Ward, Y. L., Johnson, W. B., \& Campbell, C. D. (2004). Practitioner research vertical teams: A model for mentoring in practitioner-focused doctoral programs. The Clinical Supervisor, 23(1), 179-190.

Walker, E. W., Golde, C. M., Jones, L., Bueschel, A. C., \& Hutchings, P. (2008). The formation of scholars: Rethinking doctoral education for the twenty-first century. San Francisco: Jossey-Bass.

Warren, E. S. (2005). Future colleague or convenient friend: The ethics of mentorship. Counseling and Values, 49, 141-146.

Weidman, J. C., Twale, D. J., \& Stein, E. L. (2001). Socialization of graduate and professional students in higher education: A perilous passage? San Francisco, CA: Jossey-Bass.

White, S. (2007). How to find and succeed as a mentor. American Journal of Heath System-Pharmacy, 64, 1258-1259.

Why Do Graduate Students Drop Out? (2004). Chronicle of Higher Education, 50 (22), B17.

\section{Biographies}

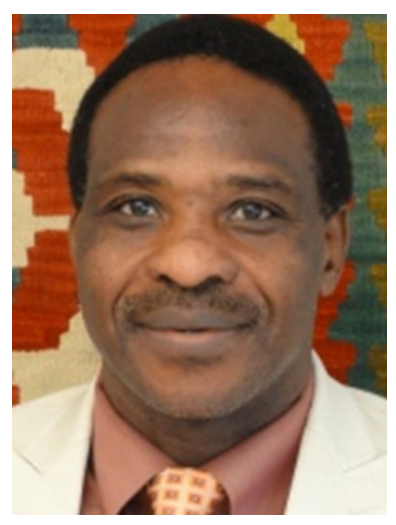

Dr. Joshua Gisemba Bagaka's is a Professor of Educational Research Design and Statistics and Director of Assessment of Student Learning at Cleveland State University. Professor Bagaka's received his Masters of Science in Probabilities and Statistics and a Ph.D. in Educational Research Design and Statistics both from Michigan State University. He also served, for seven years as the Director of the Ph. D in Urban Education program at Cleveland State University. Professor Bagaka's was also African Regional Research Fulbright Scholar to Kenya from August 2010 to April 2011.

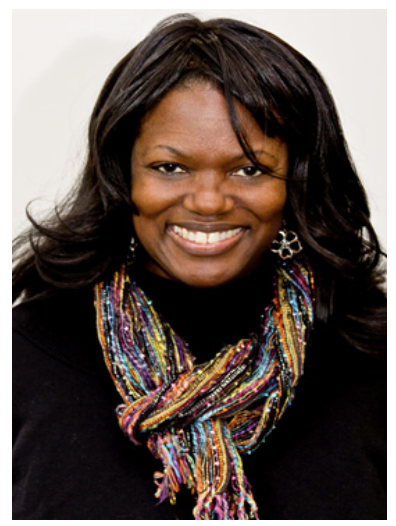

Natale Badillo is a doctoral resident in private practice with many years of psychological and psychoeducational testing experience in public school, hospital, and private practice settings. Natale's specialty area of practice is assessment with children, adolescents, and adults. Natale received her undergraduate degree at Dartmouth College, and her Masters' degree at the University of Akron. She has received her doctoral training in Counseling Psychology at Cleveland State University and is currently working on her dissertation research in the area of dynamic IQ assessment. During her studies at Cleveland State, Natale has also developed a research interest relating to the experiences of doctoral students in training. 


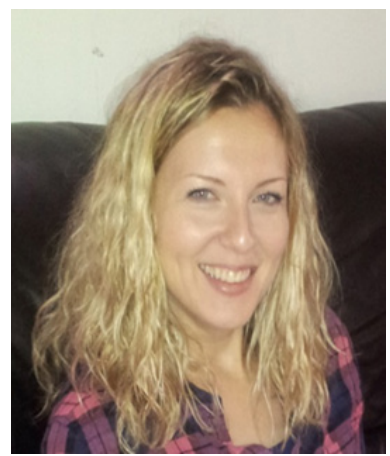

Irina Bransteter is a doctoral student in counseling psychology at Cleveland State University. She is currently completing her internship at a community mental health agency in Cleveland. Irina received her bachelor degree in psychology and a master degree in clinical psychology from Cleveland State University. Her main research interest focuses on war and exile experiences of refugees from the area of former Yugoslavia. For several years she worked as a research and graduate assistant at Cleveland State University and has taught Foundations of Clinical Medicine/Medical Interviewing Skills as an adjunct professor for the Northeast Ohio Medical University.

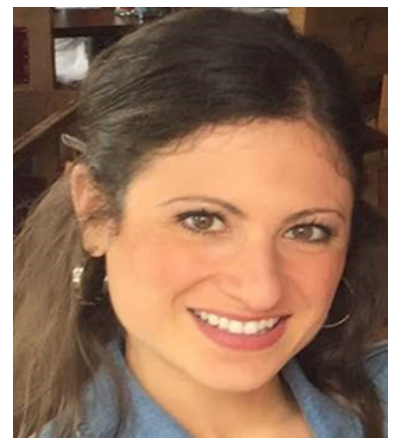

Dr. Sarah Rispinto is currently a post-doctoral psychology fellow at the Cleveland Clinic. She earned her Master's degree from John Carroll University in Community Counseling and a Ph.D. from Cleveland State University in Urban Education, specializing in Counseling Psychology. Her main research interests include: chronic pain, vocational psychology, and depression/anxiety. 